\title{
Reduced maximal aerobic capacity after COVID-19 in young adult recruits, Switzerland, May 2020
}

Giovanni Andrea Gerardo Crameri ${ }^{1}$, Michel Bielecki ${ }^{1,2}$, Roland Züst ${ }^{3}$, Thomas Werner Buehrer ${ }^{1}$, Zeno Stanga ${ }^{1,4}$, Jeremy Werner Deuel $^{1,5}$

1. Swiss Armed Forces, Medical Services, Ittigen, Switzerland

2. University of Zurich, Institute for Epidemiology, Biostatistics and Prevention Institute, Travel Clinic, Zürich, Switzerland

3. Federal Office for Civil Protection FOCP, Spiez Laboratory, Spiez, Switzerland

4. Department of Diabetes, Endocrinology, Nutritional Medicine and Metabolism, Inselspital, Bern University Hospital and University of Bern, Bern, Switzerland

5. University of Cambridge, Department of Haematology and Wellcome - MRC Cambridge Stem Cell Institute, Jeffrey Cheah Biomedical Centre, Cambridge, United Kingdom

Correspondence: Jeremy Werner Deuel (jd862@cam.ac.uk)

Citation style for this article:

Crameri Giovanni Andrea Gerardo, Bielecki Michel, Züst Roland, Buehrer Thomas Werner, Stanga Zeno, Deuel Jeremy Werner. Reduced maximal aerobic capacity after COVID-19 in young adult recruits, Switzerland, May 2020. Euro Surveill. 2020;25(36):pii=2001542. https://doi.org/10.2807/1560-7917.ES.2020.25.36.2001542

Article submitted on 13 Aug 2020 / accepted on 10 Sep 2020 / published on 10 Sep 2020

In March 2020, we observed an outbreak of COVID-19 among a relatively homogenous group of 199 young (median age 21 years; $87 \%$ men) Swiss recruits. By comparing physical endurance before and in median 45 days after the outbreak, we found a significant decrease in predicted maximal aerobic capacity in COVID-19 convalescent but not in asymptomatically infected and SARS-CoV-2 naive recruits. This finding might be indicative of lung injury after apparently mild COVID-19 in young adults.

The 2019 coronavirus disease (COVID-19) caused by the severe acute respiratory syndrome coronavirus 2 (SARS-CoV-2) emerged as a pandemic in late 2019, and is ongoing at the time of writing. Long-term sequelae of COVID-19 are still unknown. Pulmonary sequelae impairing physical fitness have been described predominantly for hospitalised patients with COVID-19 [1-3]. Although lung lesions have also been described in asymptomatically infected individuals [3-5], it is yet unclear if these observations correlate with a measurable functional deficit in physical fitness. We performed a well-established and validated physical fitness test [6] before and after an outbreak of COVID-19 among young adult Swiss recruits. By measuring the change in predicted maximal aerobic capacity $\left(\mathrm{VO}_{2} \mathrm{max}\right)$ of not infected, asymptomatically infected and convalescent COVID-19 individuals, we found a decrease in $\mathrm{VO}_{2}$ max among COVID-19 convalescent but not among asymptomatically and not infected recruits.

\section{Description of included recruits and physical fitness tests}

We previously described a COVID-19 outbreak at a Swiss Armed Forces Base affecting a cohort of young, predominantly male recruits ( 173 men, 26 women) with a median age of 21 years (range: 18-27). Throughout military training, recruits who showed symptoms had to immediately report to our clinic where they were swabbed (oronasopharyngeal) and tested for SARS-CoV-2 by reverse transcriptase quantitative PCR (RT-qPCR) for the nsp12 and E-gene. The immune response was measured with commercial enzymelinked immunosorbent assay kits for IgM, IgG (both from EDI diagnostics, San Diego, United States) and IgA (Euroimmun, Lübeck, Germany). Additionally, we performed cross-sectional sampling on 14 April 2020 to determine the rate of asymptomatic infections [7].

Here we included 199 recruits of two heavily affected companies with available information on SARS-CoV-2 status. Recruits of a further company that was not affected by the outbreak were excluded, since they had a significantly different sex ratio (only men) from the included companies. Participants were grouped by infection status into convalescent recruits with symptomatic confirmed COVID-19 $(n=68)$, asymptomatic cases with evidence of viral infection by either PCR or serology $(n=77)$ and a naive group without clinical symptoms or laboratory evidence of SARS-CoV-2 infection $(n=54)$.

The median time between COVID-19 diagnosis and the fitness test was 45 days (range: $31-58$ days), while the baseline test had been performed 3 months before the COVID-19 outbreak at the Armed Forces Base (Table). Paired sport data at baseline and after the COVID-19 outbreak were available for 139 (70\%) of the participants. The main reason for missing sport data was medical dispensation, however, the rate of missing data was similar throughout all groups.

Aerobic endurance, trunk muscle, and upper extremity strength are measured by a progressive endurance 
Characteristics of participating recruits, Switzerland, May 2020

\begin{tabular}{|c|c|c|c|c|c|c|c|c|c|}
\hline \multirow{2}{*}{$\begin{array}{l}\text { Characteristics } \\
\text { Recruits (n, \%) }\end{array}$} & \multicolumn{2}{|c|}{ All groups } & \multicolumn{2}{|c|}{ SARS-CoV-2 naive } & \multicolumn{2}{|c|}{$\begin{array}{l}\text { Asymptomatically } \\
\text { infected }\end{array}$} & \multicolumn{2}{|c|}{$\begin{array}{c}\text { COVID-19 } \\
\text { convalescents }\end{array}$} & \multirow{2}{*}{$\frac{p \text { value }}{\text { NA }}$} \\
\hline & 199 & $100 \%$ & 54 & $27 \%$ & 77 & $39 \%$ & 68 & $34 \%$ & \\
\hline $\begin{array}{l}\text { Recruits with complete } \\
\text { sport data (n, \%) }\end{array}$ & 139 & $70 \%$ & 36 & $67 \%$ & 55 & $67 \%$ & 48 & $71 \%$ & $\mathrm{NS}^{\mathrm{a}}$ \\
\hline Age $\left(\right.$ years) ${ }^{b}$ & \multicolumn{2}{|c|}{20.7 (19.9 to 21.8$)$} & \multicolumn{2}{|c|}{$20.8(20.2$ to 22.0$)$} & \multicolumn{2}{|c|}{20.8 (19.9 to 21.9) } & \multicolumn{2}{|c|}{$20.3(19.8$ to 21.5$)$} & NA \\
\hline $\begin{array}{l}\text { Fraction of female recruits } \\
(\mathrm{n}, \%)\end{array}$ & 25 & $13 \%$ & 6 & $11 \%$ & 10 & $13 \%$ & 9 & $13 \%$ & NA \\
\hline BMI $\left(\mathrm{kg} / \mathrm{m}^{2}\right)^{\mathrm{b}}$ & \multicolumn{2}{|c|}{$22.7(21.4$ to 24.8$)$} & \multicolumn{2}{|c|}{$22.2(20.5$ to 23.9$)$} & \multicolumn{2}{|c|}{$23.1(21.9$ to 25.6$)$} & \multicolumn{2}{|c|}{$23.7(21.9$ to 25.5$)$} & NA \\
\hline $\begin{array}{l}\mathrm{VO}_{2} \max \text { at baseline }(\mathrm{ml} / \\
\left.\mathrm{min}^{2} / \mathrm{kg}\right)^{\mathrm{b}}\end{array}$ & \multicolumn{2}{|c|}{$43.3(41.8$ to 45.1$)$} & \multicolumn{2}{|c|}{$43.5(42.4$ to 45.0$)$} & \multicolumn{2}{|c|}{$42.8(41.7$ to 44.8$)$} & \multicolumn{2}{|c|}{$43.7(41.5$ to 46.0$)$} & $\mathrm{NS}^{\mathrm{c}}$ \\
\hline $\mathrm{VO}_{2} \max (\mathrm{ml} / \mathrm{min} / \mathrm{kg})^{\mathrm{b}}$ & \multicolumn{2}{|c|}{$42.6(40.8$ to 44.5$)$} & \multicolumn{2}{|c|}{$42.8(42.2$ to 45.0$)$} & \multicolumn{2}{|c|}{$42.9(40.9$ to 44.2$)$} & \multicolumn{2}{|c|}{41.8 (39.9 to 44.6$)$} & $N^{c}(p=0.06)$ \\
\hline $\begin{array}{l}\text { Change in } \mathrm{VO}_{2} \max (\mathrm{ml} / \\
\mathrm{min} / \mathrm{kg})^{\mathrm{b}}\end{array}$ & \multicolumn{2}{|c|}{$-0.25(-2.4$ to 1.2$)$} & \multicolumn{2}{|c|}{$+0.1(-1.2$ to 1.7$)$} & \multicolumn{2}{|c|}{$o(-2.0$ to 1.3$)$} & \multicolumn{2}{|c|}{$-0.9(-3.2$ to 0.5$)$} & $p=0.005^{c}$ \\
\hline $\begin{array}{l}\text { Fraction of recruits with } \\
\text { more than } 10 \% \text { loss in } \\
\mathrm{VO}_{2} \max (n, \%)\end{array}$ & 10 & $7.2 \%$ & 0 & $0.0 \%$ & 1 & $1.9 \%$ & 9 & $18.8 \%$ & $p<0.001^{a}$ \\
\hline $\begin{array}{l}\text { Fraction of recruits with a } \\
\text { gain of more than } 10 \% \text { in } \\
\mathrm{VO}_{2} \max (\mathrm{n}, \%)\end{array}$ & 9 & $6.5 \%$ & 5 & $13.9 \%$ & 4 & $7.6 \%$ & 0 & $0 \%$ & $p=0.02^{a}$ \\
\hline $\begin{array}{l}\text { Upper extremity strength } \\
\text { SSP }(m)^{b}\end{array}$ & \multicolumn{2}{|c|}{$5.8(5.0$ to 6.3$)$} & \multicolumn{2}{|c|}{$5.8(5.4$ to 6.2$)$} & \multicolumn{2}{|c|}{$5.8(4.9$ to 6.5$)$} & \multicolumn{2}{|c|}{$6.0(5.0$ to 6.5$)$} & $\mathrm{NS}^{\mathrm{c}}$ \\
\hline $\begin{array}{l}\text { Trunk strength } \\
\text { PBT (s) }\end{array}$ & \multicolumn{2}{|c|}{$120(82$ to 180$)$} & \multicolumn{2}{|c|}{$130(115$ to 184$)$} & \multicolumn{2}{|c|}{120 (81 to 168$)$} & \multicolumn{2}{|c|}{$120(81$ to 149$)$} & $\mathrm{NS}^{\mathrm{c}}$ \\
\hline
\end{tabular}

COVID-19: coronavirus disease; NA: not applicable; NS: not significant; PBT: prone bridge test; SSP: seated shot put test; SARS-CoV-2: severe acute respiratory syndrome coronavirus $2 ; \mathrm{VO}_{2}$ max: maximal aerobic capacity.

a Fisher's exact test.

b The median and $25 \%-75 \%$ percentiles in brackets.

' Student's t-test comparing COVID-19 patients to the other two groups.

run (PER), prone bridge test (PBT) and seated shot put test (SSP), respectively. Using the final running velocity of the PER, predicted maximal aerobic capacity $\left(\mathrm{VO}_{2}\right.$ max $)$ can be calculated $[8,9]$. Since the local outbreak occurred in-between the two sets of tests, we were able to assess physical fitness before and after infection with SARS-CoV-2. Statistical significance testing for differences of scalar variables (e.g. VO, max) between the groups were performed with Student's t-test and differences in the contingency tables were tested with Fisher's exact test. $p$ values smaller than 0.05 were considered as statistically significant.

\section{Decreased maximal aerobic capacity in COVID-19 convalescent recruits}

We observed a statistically significant decrease in $\mathrm{VO}_{2}$ max among COVID-19 convalescents compared with naive and asymptomatically infected recruits (Figure). While the median $\mathrm{VO}_{2}$ max stayed unchanged for most recruits, a significant decrease in $\mathrm{VO}_{2}$ max of $-0.9 \mathrm{ml} / \mathrm{min} / \mathrm{kg}$ was observed in COVID-19 convalescents if compared with their individual baseline measurements before the local outbreak (Figure). Not only the difference but also the absolute $\mathrm{VO}_{2}$ max was lower in convalescent as compared with naive recruits $(p=0.02$, data not shown), although significance was lost if COVID-19 convalescents were compared with the combined group of asymptomatic and naive recruits $(p=0.06$, Table).

Neither of the strength tests (PBT and SSP) differed significantly between the three groups (Table).

During military training, fitness is expected to generally increase. We observed an increase in $\mathrm{VO}_{2}$ max of more than $10 \%$ in nearly $14 \%$ of the naive recruits and nearly $8 \%$ in the asymptomatic group, while none of the COVID-19 convalescent recruits had an increase of more than $10 \%$. On the contrary, $19 \%$ of the COVID19 convalescents had a decrease of more than $10 \%$ in $\mathrm{VO}_{2}$ max, while none of the naive recruits showed such a decrease. While the overall effect of COVID-19 on $\mathrm{VO}_{2}$ max might be subtle, a significant subset of patients seem to have lost more than $10 \%$ of their initial aerobic capacity.

These findings indicate a specific decrease in aerobic capacity affecting COVID-19 convalescent recruits compared with naive as well as asymptomatically infected ones. $\mathrm{VO}_{2}$ max before the COVID-19 outbreak was very similar between the groups, excluding a selection bias for preexisting lower scores. 


\section{FIGURE}

Difference in predicted maximal aerobic capacity before and after COVID-19 outbreak by infection status among recruits, Switzerland, May 2020

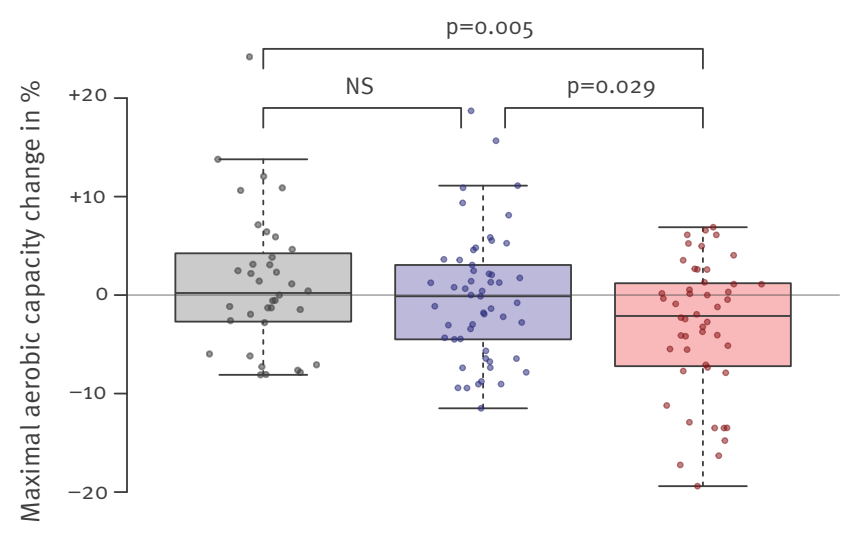

Infection status

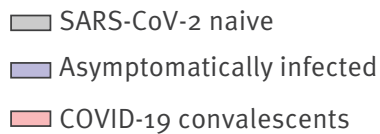

COVID-19: coronavirus disease; NS: not significant; SARS-CoV-2: severe acute respiratory syndrome coronavirus 2 .

$\mathrm{p}$ values were calculated by Student's t-test.

\section{Ethical statement}

All procedures involving human participants were conducted in accordance with the ethical standards of the Declaration of Helsinki, as revised in 2013. The study protocol was approved by the ethical committee of the Canton of Ticino, Switzerland (BASEC-ID 2020-00623 CE 3609). Written informed consent of all participants was obtained after oral explanations provided in their native language (German, French or Italian).

\section{Discussion and conclusions}

To our knowledge, changes in endurance or strength following SARS-CoV-2 infection, symptomatic or not, have not been described until now. We showed reduced aerobic capacity in young adult recruits 1 to 2 months after symptomatic COVID-19 while physical strength was unaffected. Ca $19 \%$ of COVID-19 convalescent recruits showed a decrease of $\mathrm{VO}_{2}$ max of more than $10 \%$ as compared with baseline before infection. Although our data do not explain the pathophysiology behind these findings, reduced $\mathrm{VO}_{2}$ max is a hallmark of interstitial lung disease [10]. SARS-CoV-2 infection has been described to induce lung damage, even in asymptomatic cases [4]. This indicates the importance of further long-term follow-up studies to assess the extent and duration of the sequelae, as well as of infection prevention to avoid these long-term consequences.

Physical deconditioning or demotivation may explain impaired fitness or compliance, respectively. The COVID-19 outbreak had a mental and physical impact on military personnel: stringent physical distancing measures, quarantine and isolation restricted possibilities for physical activity, and lowered morale. However, we would expect deconditioning and lowered test adherence due to demotivation to affect the results for both aerobic capacity and physical strength similarly [11], which was not the case with our observations.

Other than the described endurance run, we could neither conduct more specific tests (such as spirometry) nor perform serial imaging to identify our results' pathophysiology. The cohort has meanwhile been dissolved due to the end of military training, thus such studies are difficult to perform in our study group. Since we studied a relatively homogeneous cohort of young, otherwise healthy, and predominantly male adults, our findings might not be applicable to other population groups.

Our observations were made within 1 to 2 months after the diagnosis of COVID-19 and follow-up studies should be conducted to determine whether the reduction in $\mathrm{VO}_{2}$ max is reversible. With ca 44,900 confirmed COVID-19 cases in Switzerland [12] as well as over 2.4 million in the European Union and Economic Area and the United Kingdom, respectively [13] and still increasing case numbers, evaluating possible long-term consequences of COVID-19 is becoming more important by the day.

\section{Acknowledgements}

We thank Michele Dariz and Daniele Meyerhofer (Swiss Armed Forces, Sanitary Medical School, Airolo, Switzerland) for providing the sport test data.

Funding: This work was funded by the Center of Competence in Military and Disaster Medicine of the Swiss Armed Forces and a Postdoc Mobility Grant of the Swiss National Science Foundation (P400PB_183859 to JWD).

\section{Conflict of interest}

None declared.

Authors' contributions

GAGC, TWB, ZS and JWD designed the study. GAGC, MB, RZ and JWD collected and analysed the data. GAGC wrote the first draft.

\section{References}

1. Frija-Masson J, Debray M-P, Gilbert M, Lescure F-X, Travert F, Borie R, et al. Functional characteristics of patients with SARS-CoV-2 pneumonia at 30 days post-infection. Eur Respir J. 2020;56(2):2001754. https://doi.org/10.1183/13993003.017542020 PMID: 32554533

2. Mo X, Jian W, Su Z, Chen M, Peng H, Peng P, et al. Abnormal pulmonary function in COVID-19 patients at time of hospital discharge. Eur Respir J. 2020;55(6):2001217. https://doi. org/10.1183/13993003.01217-2020 PMID: 32381497

3. Li Y, Shi J, Xia J, Duan J, Chen L, Yu X, et al. Asymptomatic and Symptomatic Patients With Non-severe Coronavirus Disease (COVID-19) Have Similar Clinical Features and Virological 
Courses: A Retrospective Single Center Study. Front Microbiol. 2020;11:1570. https://doi.org/10.3389/fmicb.2020.01570 PMID: 32754137

4. Meng $\mathrm{H}$, Xiong R, He R, Lin W, Hao B, Zhang L, et al. CT imaging and clinical course of asymptomatic cases with COVID-19 pneumonia at admission in Wuhan, China. J Infect. 2020;81(1):e33-9. https://doi.org/10.1016/j.jinf.2020.04.004 PMID: 32294504

5. Pan Y, Yu X, Du X, Li Q, Li X, Qin T, et al. Epidemiological and Clinical Characteristics of 26 Asymptomatic Severe Acute Respiratory Syndrome Coronavirus 2 Carriers. J Infect Dis. 2020;221(12):1940-7. https://doi.org/10.1093/infdis/jiaa205 PMID: 32318703

6. Gassmann NN, Matthes KL, Eppenberger P, Brabec M,

Panczak R, Zwahlen M, et al. Residential Altitude Associates With Endurance but Not Muscle Power in Young Swiss Men. Front Physiol. 2020;11:860. https://doi.org/10.3389/ fphys.2020.00860 PMID: 32792981

7. Bielecki M, Züst R, Siegrist D, Meyerhofer D, Crameri GAG, Stanga ZG, et al. Social distancing alters the clinical course of COVID-19 in young adults: A comparative cohort study. Clin Infect Dis. 2020;ciaa889. https://doi.org/10.1093/cid/ciaa889 PMID: 32594121

8. Wyss T, Marti B, Rossi S, Kohler U, Mader U. Assembling and verification of a fitness test battery for the recruitment of the Swiss Army and nation-wide use. Schweizerische Zeitschrift fur Sportmedizin und Sporttraumatologie.2007;55(4):126.

9. Wyss T, Roos L, Studer F, Mäder U, Beuchat C, Staub K. Development of physical fitness performance in young Swiss men from 2006 to 2015. Scand J Med Sci Sports. 2019;29(4):586-96. https://doi.org/10.1111/sms.13376 PMID: 30586205

10. Wehr KL, Johnson RL Jr. Maximal oxygen consumption in patients with lung disease. J Clin Invest. 1976;58(4):880-90. https://doi.org/10.1172/JCl108541 PMID: 965494

11. Mulder E, Clément G, Linnarsson D, Paloski WH, Wuyts FP, Zange J, et al. Musculoskeletal effects of 5 days of bed rest with and without locomotion replacement training. Eur J Appl Physiol. 2015;115(4):727-38. https://doi.org/10.1007/s00421014-3045-0 PMID: 25425257

12. Federal Office of Public Health (FOPH). New coronavirus: Situation in Switzerland. Bern: FOPH. [Accessed: 8 Sep 2020]. Available from: https://www.bag.admin.ch/bag/en/home/ krankheiten/ausbrueche-epidemien-pandemien/aktuelleausbrueche-epidemien/novel-cov/situation-schweiz-undinternational.html

13. European Centre for Disease Prevention and Control (ECDC). COVID-19 pandemic. Stockholm: ECDC. [Accessed: 8 Sep 2020]. Available from: https://www.ecdc.europa.eu/en/ covid-19-pandemic

\section{License, supplementary material and copyright}

This is an open-access article distributed under the terms of the Creative Commons Attribution (CC BY 4.0) Licence. You may share and adapt the material, but must give appropriate credit to the source, provide a link to the licence and indicate if changes were made.

Any supplementary material referenced in the article can be found in the online version.

This article is copyright of the authors or their affiliated institutions, 2020. 